\title{
Snow saltation threshold measurements in a drifting-snow wind tunnel
}

\author{
Andrew CLIFTON, Jean-Daniel RÜEDI, Michael LEHNING \\ WSL Swiss Federal Institute for Snow and Avalanche Research SLF, Flüelastrasse 11, CH-7260 Davos Dorf, Switzerland \\ E-mail: clifton@slf.ch
}

\begin{abstract}
Wind tunnel measurements of snowdrift in a turbulent, logarithmic velocity boundary layer have been made in Davos, Switzerland, using natural snow. Regression analysis gives the drift threshold friction velocity $\left(u_{*}\right)$, assuming an exponential drift profile and a simple drift to friction velocity relationship. Measurements over 15 snow covers show that $u_{* \mathrm{t}}$ is influenced more by snow density and particle size than by ambient temperature and humidity, and varies from 0.27 to $0.69 \mathrm{~m} \mathrm{~s}^{-1}$. Schmidt's threshold algorithm and a modified version used in SNOWPACK (a snow-cover model) agree well with observations if small bond sizes are assumed. Using particle hydraulic diameters, obtained from image processing, Bagnold's threshold parameter is 0.18. Roughness lengths $\left(z_{0}\right)$ vary between snow covers but are constant until the start of drift. Threshold roughness lengths are proportional to $u_{* t}^{2}$. The influence of macroscopic objects on the roughness length is shown by the lower values measured over the smooth and flat snow surface of the wind tunnel $\left(0.04 \leq z_{0} \leq 0.13 \mathrm{~mm}\right)$, compared to field measurements. Mean drifting-snow grain sizes for mainly new and partly decomposed snow are 100-175 $\mu \mathrm{m}$, and independent of surface particle size.
\end{abstract}

\section{INTRODUCTION}

This paper describes the results of a series of experiments investigating the form of the wind velocity boundary layer over a snow surface, with and without drift. This information is essential to help calculate the energy balance at the snow surface and also to assess mass movement of snow by wind. The process of drift is important both over relatively flat terrain, such as Antarctic regions, where it contributes to mass balance, and also in mountainous terrain, where accumulation on steep slopes can contribute to the danger of avalanches.

The velocity boundary layer over a surface is often described by a log-law, where the wind speed at a particular height is a function of the surface friction velocity, $u_{*}$, and aerodynamic roughness length, $z_{0}$ (Stull, 1988). The parameters $u_{*}$ and $z_{0}$ are then used to model the fluxes of heat and water vapour from the surface, which are important, not only for snowpack development (Marks and Dozier, 1992; Lehning and others, 2002b), but also for mass-balance calculations (Cline, 1997; Liston and Sturm, 1998; Box and others, 2004).

Aerodynamically rough, solid surfaces have roughness lengths independent of $u_{*}$ (Schlichting and Gersten, 2003). The same does not always hold over granular surfaces, such as snow or sand; above the threshold friction velocity, $u_{* t}$, particles will be entrained and transported by drift. At low wind speeds, this drift will be predominantly saltation, where particles follow parabolic paths over the surface (Bagnold, 1941, p. 10-37). These drifting particles increase the aerodynamic roughness of the surface. Owen (1964) summarized earlier research relating to the aerodynamic effects of drifting particles, and developed a theoretical framework to explain this effect. Together, these suggest two regimes for flow over granular surfaces: a region where $u_{*} \leq u_{* \mathrm{t}}$ and $z_{0}$ is constant, and another where $u_{*} \geq u_{* \mathrm{t}}$ and $z_{0}$ increases when measured above the drifting material. Implementing this in a model then requires $z_{0}$ over the stable surface, $u_{* \mathrm{t}}$ and the dependence of $z_{0}$ on $u_{*}$ when $u_{*} \geq u_{* \mathrm{t}}$.
Current models of the boundary layer over snow vary in their treatment of $z_{0}$. In some cases it is assumed constant (Cline, 1997; Li and Pomeroy, 1997b; Reijmer and others, 2003; Garen and Marks, 2005; Kunstmann and Stadler, 2005) and in others it is affected by snowdrift (Liston and Sturm, 1998; Lehning and others, 2000). For large-scale climate modelling over large regions, assuming a fixed $u_{* \mathrm{t}}$ and/or $z_{0}$ may be valid because surface conditions only change within narrow bands, but models can still be significantly influenced by $z_{0}$ (e.g. Reijmer and others, 2003).

Field measurements (Stearns and Weidner, 1993; Bintanja and Van den Broeke, 1995; Andreas and others, 2004) of the boundary layer over snow-covered ice do show an increase in $z_{0}$ with $u_{*}$, but their results do not distinguish between periods with or without drift and do not include surface snow characterization. Oura and others (1967) and Kobayashi $(1969,1972)$ measured $z_{0}$ over snow with and without drift, and noted a dependency of $z_{0}$ upon the presence of drift. Oura and others measured identical $z_{0}$ during snowfall and over a non-drifting snow surface, showing that it is drifting particles that increase $z_{0}$, not just the presence of particles in the air from precipitation. Results from König (1985) include details of the degree of drift over an ice sheet, but give no information about the snow surface or transport rates. Doorschot and others (2004) report some characteristics of the local snow cover during field measurements of $u_{* \mathrm{t}}$ and $z_{0}$, but these were in mountainous terrain. Unfortunately, none of these studies allow terrain, surface and saltation influences to be separated.

Bagnold (1941, p. 57-76) measured boundary layers over still and drifting sand and provided much of the groundwork for current steady-state models of sand drift (e.g. Sørensen, 1991). The same physical basis has been applied to models of snowdrift, such as SnowTran-3D (Liston and Sturm, 1998) and the snowdrift index in SNOWPACK (a snow-cover development simulator; Lehning and others, 2000). In SnowTran-3D, $u_{* t}$ is constant, while in SNOWPACK it is calculated from a modified version of Schmidt's (1980) drift 
threshold algorithm, which estimates $u_{* t}$ from snow characteristics. Other models of drifting snow have been developed from first principles (Doorschot and Lehning, 2002), while Shao and Li (1999) and Nemoto and Nishimura (2004) coupled large-eddy simulations using the NavierStokes equations with Lagrangian particle treatment to model snow and sand transport, respectively. Drift prediction models using weather station data have also been developed for meteorological services ( $\mathrm{Li}$ and Pomeroy, $1997 \mathrm{a}, \mathrm{b})$, but these tend to consider drift as a probabilistic event and relate conditions to a measurement height, rather than surface conditions $u_{*}$ and $z_{0}$.

No study that we are aware of has related the form of the velocity boundary layer over a flat snow surface to the snow itself, or repeatedly measured $u_{* t}$ and snow characteristics together. This is easier in a wind tunnel than in field experiments, as mean flow is, by definition, in one direction and the boundary layer which is formed is only influenced by snow of known characteristics. There are no additional effects from terrain or atmospheric stability which could influence results.

We describe a series of experiments designed to measure boundary layer flow over natural snow under controlled conditions in a wind tunnel at the Swiss Federal Institute for Snow and Avalanche Research SLF in Davos, Switzerland. An overview of the theory of boundary layer flow over snow is given, and then compared to first measurements from the wind tunnel. The influence of weather and snow properties on measured boundary layer friction velocities and roughness lengths up to and at the drift threshold is examined. Finally several algorithms for $u_{* \mathrm{t}}$ (Bagnold, 1941; Schmidt, 1980; Li and Pomeroy, 1997a) are compared to our results.

\section{THEORY}

The time-averaged, turbulent, neutrally stratified, velocity boundary layer over an immobile rough surface can be described by a log-law. This describes a logarithmic profile, where the velocity, $u$, at a height $z$ is a function of the surface roughness length, $z_{0}$, and the friction velocity, $u_{*}$, so that

$$
u(z)=\frac{u_{*}}{\kappa} \ln \left(\frac{z}{z_{0}}\right),
$$

where $\kappa$ is the von Kármán constant, taken here as 0.41 (for a review of experimental results, see Garratt, 1994, p. 289) and $u_{*}$ and $z_{0}$ can be determined from velocity and height measurements. This result depends on the validity of the loglaw profile and the accuracy of the measurements.

Surfaces are generally divided into three hydraulic regimes, depending on the height to which wall roughness penetrates the different regions of the boundary layer, and the influence they have on the drag. Wall roughness elements can be characterized according to their size relative to the wall layer thickness, $\delta_{\mathrm{v}}$, where $\delta_{\mathrm{v}}=\nu / u_{*}$ with $\nu$ the kinematic viscosity. If the roughness elements of size $d$ are similar in size to the wall layer thickness, i.e. $\delta_{\mathrm{v}} / d \approx 1$, the elements are submerged in the viscous sub-layer of the boundary layer. In this case, the roughness elements do not affect the wall drag and the wall is considered hydraulically smooth. The limit to this regime is $d / \delta_{v}=5$ (Schlichting and Gersten, 2003, p. 522). As $d / \delta_{v}$ increases, the roughness elements project out of the viscous sub-layer but do not reach the boundary with the overlap layer of the boundary layer until $z=70 \delta_{\mathrm{v}}$. This is known as the transitional flow regime and occurs while $5 \leq d / \delta_{\mathrm{v}} \leq 70$; viscous forces still influence the drag, and hence $z_{0}$ is a function of $u_{*}$. As $d / \delta_{v}$ increases further, and elements penetrate into the overlap layer, the roughness elements directly influence the wall drag. The drag is independent of the flow Reynolds number, and hence $z_{0}$ (which is an expression of the surface drag coefficient) is independent of $u_{*}$. This is known as the hydraulically rough regime; thus fully rough flow requires that surface roughness elements have a size $d \geq 70 \delta_{\mathrm{v}}$.

Schlichting and Gersten (2003, p. 530) give $z_{0}=d / 25$ in the fully rough regime when the wall is covered with densely packed sand grains over a solid surface. This can be used to calculate a roughness Reynolds number, $\operatorname{Re}_{*}=z_{0} u_{*} / \nu$, where the rough regime is $\operatorname{Re}_{*}>2.8$. By comparison, Greeley and Iversen (1985, p. 43) give $d / 30 \leq z_{0} \leq d / 8$, depending on the distribution of sand on the surface, and hence the start of the rough regime is in the range $2.33 \leq \mathrm{Re}_{*} \leq 8.75$. Andreas (1987) and Bintanja and Van den Broeke (1995) assume that the rough region is $\operatorname{Re}_{*} \geq 2.5$. Given the uncertainty about the onset of the fully rough regime in terms of $\mathrm{Re}_{*}$, it seems more sensible to use the definition of the rough regime starting at $d \geq 70 \delta_{\mathrm{v}}$.

In the wind tunnel at $-10^{\circ} \mathrm{C}$ and $835 \mathrm{hPa}, \nu$ is approximately $1.48 \times 10^{-5} \mathrm{~m}^{2} \mathrm{~s}^{-1}$. The typical $u_{*}$ is $0.3 \mathrm{~m} \mathrm{~s}^{-1}$. This gives a wall layer thickness $\delta_{\mathrm{v}}=50 \mu \mathrm{m}$, and requires that the roughness elements project at least $3.45 \mathrm{~mm}$ into the flow from a solid surface to reach the overlap region of the boundary layer. The surface of the snow is uneven and often permeable, and so occasional snow particles may protrude into the overlap region, causing a rough surface where $z_{0}$ is independent of $u_{*}$.

The surface roughness length is also affected by the presence of drifting snow particles. Owen (1964) provided a theoretical basis for the influence of drifting particles on the flow above the saltating layer. His hypothesis was that the roughness of a drifting surface should increase compared to the stable surface so the velocity at a height $z$ is given by

$$
\frac{u(z)}{u_{*}}=\frac{1}{\kappa} \ln \left(\frac{2 g z}{u_{*}^{2}}\right)+D^{\prime},
$$

where $D^{\prime}$ is a constant and $g$ is the acceleration due to gravity, $9.81 \mathrm{~m} \mathrm{~s}^{-2}$. Equating this to the more familiar form in Equation (1) gives

$$
z_{0}=C \frac{u_{*}^{2}}{2 g},
$$

where the constant $C$ is $\exp \left(-D^{\prime} \kappa\right)$. From a survey of data in the literature, Owen (1964) found $D^{\prime}$ to be 9.7, i.e. $C=0.021$ over sand and soil. A literature survey by Tabler (1980) gave $0.011 \leq C \leq 0.028$ for smooth snow covers with long fetch. König (1985) found $C=0.012$ over snowcovered ice, while Bintanja and Van den Broeke (1995) measured $C=0.032$ under similar conditions. Liston and Sturm (1998) used $C=0.12$ for flow over 'topographically variable' terrain. Charnock (1955) is often referenced in place of Owen, as his equation has the same form but was developed to explain $z_{0}$ over waves, not saltating surfaces.

At the onset of saltation, Equations (2) and (1) must both apply. Therefore, $z_{0}$ before drift (if it is constant) can be used to calculate $u_{* t}$ from Equation (3). For $u_{*}>u_{* t}$, the minimum $z_{0}$ which is seen by measurements above the saltation layer is given by Equation (3). Owen's relationship gives the 
minimum $z_{0}$ because topographic influences could increase the apparent $z_{0}$ at a given $u_{*}$, as was observed by Doorschot and others (2004).

The total mass flux, $Q$, from a loose surface has been measured for sand by Bagnold (1941, p. 69-70) and Shao and Raupach (1992), and for snow by Nishimura and others, (1998), Nishimura and Hunt (2000) and Nishimura and Nemoto (2005) and results give a relationship of the form:

$$
\begin{array}{ll}
Q=0 & \text { for } u_{*}<u_{* \mathrm{t}} \\
Q=a\left(u_{*}-u_{* \mathrm{t}}\right)^{3} & \text { for } u_{*} \geq u_{* \mathrm{t}},
\end{array}
$$

where $a$ is a constant. From dimensional considerations, $a$ is given by $\alpha_{\mathrm{m}} \rho_{\mathrm{p}} d / g$, where $\rho_{\mathrm{p}}$ is the density of the particle and $\alpha_{\mathrm{m}}$ is some constant for a particular surface.

Drift in the wind tunnel is measured using a snow particle counter (SPC). SPC measurements in the wind tunnel do not cover the entire saltation layer. The SPC measures the flux over a $2.5 \mathrm{~mm}$ high window, positioned $50 \mathrm{~mm}$ above the snow surface, and so the effect of moving the saltating cloud past the SPC has to be included. Separating the mass flux at a height $z$ into a total mass flux $Q\left(u_{*}\right)$ and a profile function $\Phi\left(u_{*}, z\right)$ which defines the form of the drifting flux with height, we can define a general form of the mass flux at a height $q(z)$ as a function of $u_{*}$ and $z$, which for $u_{*}>u_{* \mathrm{t}}$ is given by

$$
q(z)=Q\left(u_{*}\right) \Phi\left(u_{*}, z\right) .
$$

From the definition of saltation, there is zero horizontal mass flux at the ground and at $z=\infty$, implying a maximum at a given height. Pomeroy and Gray (1990) give the height of maximum mass flux $\left(h_{\mathrm{s}}\right)$ as $h_{\mathrm{s}}=1.6 u_{*}^{2} / 2 g$. This gives $h_{\mathrm{s}}=12 \mathrm{~mm}$ at $u_{*}=0.4 \mathrm{~m} \mathrm{~s}^{-1}$. Our SPC is at $50 \mathrm{~mm}$. Various experiments (Budd and others, 1966; Schmidt, 1982; Maeno and others, 1995; Nishimura and others, 1998; Nishimura and Hunt, 2000) have shown that the horizontal mass flux of drifting snow decays exponentially with height. This observed decay, with no near-ground maximum, may show the limits of measurement resolution or the influence of other snow transport processes. To fit our measurements, we use a parameterization of horizontal mass flux decay with increasing height. This parameterization, described as a profile function, is valid above the height of maximum transport, and was used to fit measurement data by Nishimura and Hunt (2000).

If the measurement height is $z$ and the characteristic height of the saltation system is $L$ and the integral over $0 \leq z \leq \infty$ is 1 , allowing the profile function to scale the total mass flux, the profile function is given by

$$
\Phi\left(u_{*}, z\right)=\frac{1}{L} \mathrm{e}^{\left(-\frac{z}{L}\right)} .
$$

The characteristic height, $L$, can be estimated from conservation of energy. If a particle leaves a surface with a vertical velocity $\eta u_{*}$, where $\eta$ is some constant, conservation of energy dictates that it will reach a height given by $(1 / 2 g)\left(\eta u_{*}\right)^{2}$, if external forces are zero. The parameter $2 / \eta^{2}$ is defined as $\lambda$, where $\lambda$ is a dimensionless parameter for a single experiment. Hence, $L$ is given by

$$
L=\frac{1}{\lambda g} u_{*}^{2} .
$$

Nishimura and Hunt (2000) report $\lambda=0.45$ for drifting $0.48 \mathrm{~mm}$ diameter snow, decreasing to $0.13-0.16$ for drifting ice particles.
Substituting Equations (4) and (6) into Equation (5) and then substituting $L$ from Equation (7) gives the mass flux at a single height when $u_{*}>u_{* t}$ as

$$
q(z)=a\left(u_{*}-u_{* \mathrm{t}}\right)^{3} \frac{\lambda g}{u_{*}^{2}} \mathrm{e}^{\left(-\frac{\lambda z g}{u_{*}^{2}}\right)} .
$$

The only unknowns, then, are $a$ and $u_{* t}$, which can be calculated from measurements of $u_{*}$ and $q(z)$ using regression. We take $\lambda=0.45$, but an example fit shown in Figure 3 shows that even when $\lambda$ is changed to 0.3 or 0.6 the influence on the mass flux is minimal. Using a fixed value of $\lambda$ improves the stability of the regression, as only two values, $a$ and $u_{*}$, have to be found.

At the threshold, the total aerodynamic forces acting on a particle are just sufficient to remove a snow particle from the snow surface. Bagnold (1941, p. 86) equated the moments due to aerodynamic forces on a grain and a grain's immersed weight, to calculate the threshold $u_{*}$, and showed that

$$
u_{* \mathrm{t}}=A \sqrt{\frac{\rho_{\text {ice }}-\rho_{\text {air }}}{\rho_{\text {air }}} g d},
$$

where $\rho_{\text {ice }}$ is the density of ice $\left(917 \mathrm{~kg} \mathrm{~m}^{-3}\right), \rho_{\text {air }}$ is the density of air, $d$ is the grain diameter and $A$ is the threshold parameter. Bagnold stated that for a Reynolds number of the form $\operatorname{Re}_{* d}=u_{*} d / \nu$, the threshold parameter for sand in air is constant at 0.1 for $\mathrm{Re}_{* d}>3.5$, a behaviour reported for other spherical or granular materials by Greeley and Iversen (1985, p. 78).

Schmidt (1980) suggested a formulation for $u_{* t}$ for snow which used both the snow bulk properties and microstructure. Lehning and others (2000) reformulated that relationship to give:

$$
u_{* \mathrm{t}}=\sqrt{\frac{A \rho_{\text {ice }} g d(\mathrm{SP}+1)+B \sigma \frac{N_{3} d_{b}^{2}}{d^{2}}}{\rho_{\text {air }}}} .
$$

The dimensionless constants $A$ and $B$ are 0.009 and 0.0135 , respectively, SP is the sphericity, $N_{3}$ is the mean number of bonds per particle (also known as three-dimensional coordination number), $d_{\mathrm{b}}$ is the bond diameter and $\sigma$ is a reference shear stress set to $300 \mathrm{~Pa}$. Equation (10) calculates the shear required to cause drift, which is equal to the sum of a particle mass and a shear acting on a bond. The mass term is given by $A \rho_{\text {ice }} g d(\mathrm{SP}+1)$, and the shearing term by $B \sigma\left(N_{3} d_{b}^{2} / d^{2}\right)$.

An alternative approach was taken by $\mathrm{Li}$ and Pomeroy (1997a), who gave a parameterization of the threshold $10 \mathrm{~m}$ wind speed using the air temperature as the predictive variable. Based on a fit to observations in the Canadian Prairies, Li and Pomeroy proposed that

$$
u_{\mathrm{t}}(10)=9.43+0.18 T_{\mathrm{a}}+0.0033 T_{\mathrm{a}}^{2},
$$

where $T_{\mathrm{a}}$ is the air temperature $\left({ }^{\circ} \mathrm{C}\right)$ measured $2 \mathrm{~m}$ above the surface and $u_{\mathrm{t}}(10)$ is a threshold wind speed at $10 \mathrm{~m}$ above the surface.

\section{METHOD}

The SLF wind tunnel is situated $1650 \mathrm{~m}$ a.s.I. in the Flüelatal, above Davos, Graubünden, Switzerland. The tunnel is housed in a converted Swiss Army bunker, and snowfalls are collected outside the bunker in trays. These trays are then moved intact into the bunker with as little disturbance as possible, allowing the behaviour of a natural snowpack to be 
Table 1. Weather conditions and snow characterization for wind tunnel tests. RH: relative humidity; SMP: SnowMicroPen; SP: sphericity; $\mathrm{DN}$ : dendricity

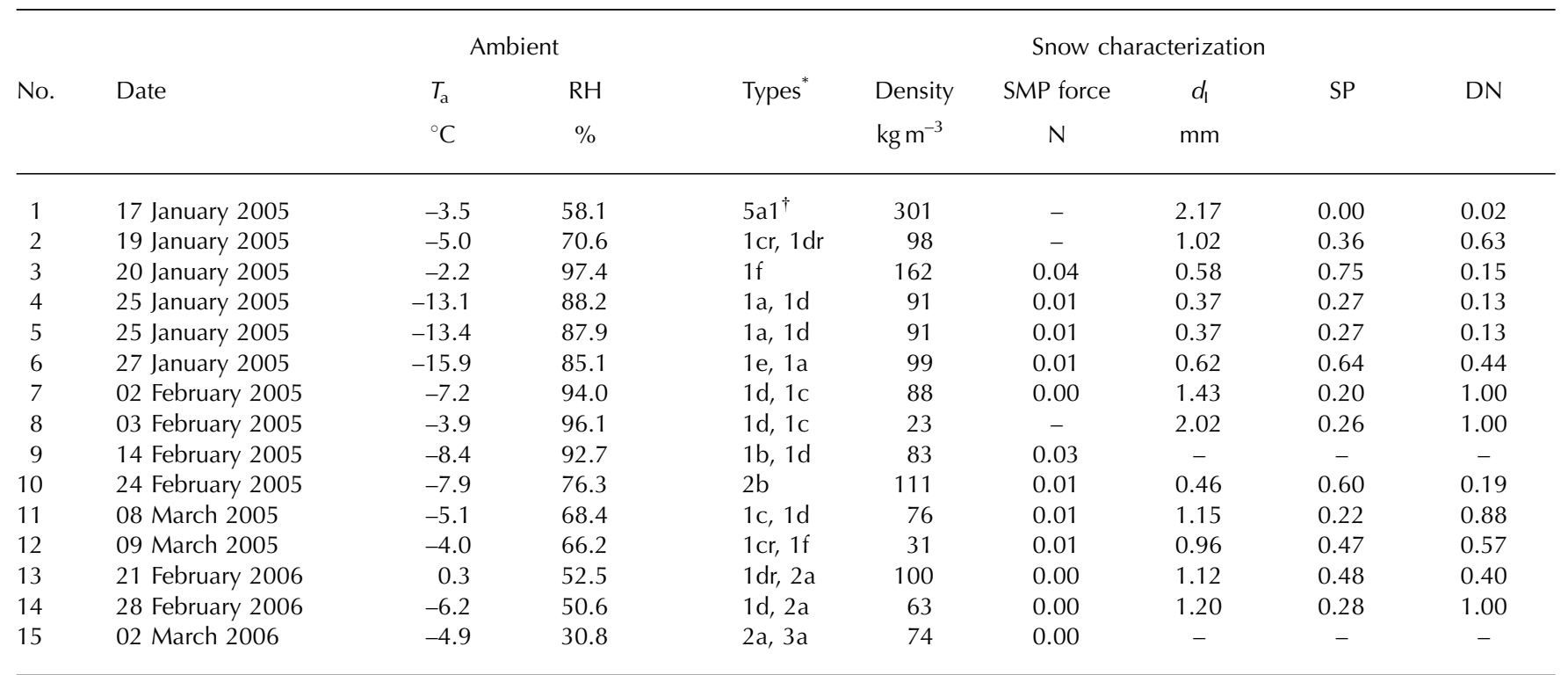

*Nomenclature is taken from the International Snow Classification scheme of Colbeck and others (1990). Suffix ' $r$ ' indicates significant riming.

tDepth hoar was dug from slopes around the wind tunnel.

investigated. Trays are used for experiments when they contain $0.06-0.16 \mathrm{~m}$ depth of undisturbed snow. One test reported here uses sieved depth hoar (see Table 1); all others use snow naturally deposited by precipitation.

The wind tunnel is $14 \mathrm{~m}$ long, with a $1 \times 1 \mathrm{~m}$ crosssection. The tunnel operates in suction, drawing air from outside the bunker through a honeycomb, nets and a $4: 1$ contraction into the tunnel. Spires mounted on the floor downstream of the contraction create large-scale vortices. These are followed by regular roughness elements for $4 \mathrm{~m}$ and then fine-fibred, long-pile carpet for $4 \mathrm{~m}$. This gives a logarithmic boundary layer approximately $0.25 \mathrm{~m}$ deep. This is followed by $4 \mathrm{~m}$ of fresh snow in trays. The height of the snow trays is adjusted so that the top of the snow coincides with the uppermost fibres of the carpet. The trays are open in the streamwise direction, allowing uninterrupted boundary layer development. A sketch of the tunnel is shown in Figure 1.

The bunker is shaded from the sun by mountains from December to March, and is not heated. The tunnel was run before each experiment to draw air into the building and cool the tunnel. The building, tunnel, outside air and snow cover are therefore in thermal equilibrium.

During the experiments described here, free-stream wind speeds (and hence $u_{*}$ ) were increased incrementally in the range $3-18 \mathrm{~m} \mathrm{~s}^{-1}$ over $\sim 30 \mathrm{~min}$, and the resulting velocity profiles and drift were measured. Free-stream wind speeds were left constant for 3-4 min between each gradual increase in speed. These constant-speed intervals are described as measurement 'plateaux'. Ambient temperature, humidity and pressure were measured at the tunnel inlet at $1 \mathrm{~Hz}$.

Initial measurements of the boundary layer were made in 2005 using two Schiltknecht MiniAir propellor-type anemometers ('MiniAirs') at 5 and $10 \mathrm{~cm}$ above the snow surface. The MiniAir velocity time series were filtered to remove transients from increasing the wind tunnel speed, but keeping the plateaux when the wind speed was kept constant. Equation (1) was used to calculate $u_{*}$ and $z_{0}$ from the mean velocity profile during the plateaux. The vertical position of these sensors increased as erosion occurred, but was unknown because of the lack of a suitable sensor. Therefore $z_{0}$ from the MiniAirs can only be used before the start of drift. The calculated $u_{*}$ after the start of drift should still be valid as the vertical separation between the anemometers is fixed by their support, although at some point the air velocity at the lower anemometer will be influenced by drift (Bagnold, 1941). Measurement plateaux were discarded once friction velocity started to decrease while the velocity at the highest anemometer increased.

A detailed boundary layer velocity profile was measured during experiments in 2006 using a total pressure rake. The rake had ten total pressure probes from $\sim 25$ to $250 \mathrm{~mm}$ above the surface, arranged to give four probes below the SPC and the rest above. It was positioned $0.30 \mathrm{~m}$ upstream from the MiniAirs and SPC. The exact height was calculated from the known position of the total pressure probes on their supporting aerofoil and the position of the aerofoil above the snow surface. A static pressure measurement was obtained from the static pressure port of a pitot-static tube on the tunnel centre line. This was subtracted from the total pressure measurements to give a dynamic pressure, $P_{\mathrm{dyn}}$. The air density, $\rho_{\text {air }}$ was calculated from the tunnel static pressure, and temperature and humidity at the inlet to the test section using the equation of state. The velocity at each point on the rake is then given by $u(z)=\sqrt{2 P_{\text {dyn }} / \rho_{\text {air }}}$. Rake velocity profiles were only measured during the plateaux when the tunnel motor speed was kept constant.

Drift was measured using a Niigaata Electric SPC-S7 optical SPC, positioned $5 \mathrm{~cm}$ above the snow at the same fetch as the anemometers. The SPC records the number of particles in 32 equivalent-diameter classes passing through the detector every second. The SPC detects particle diameters $d_{\mathrm{SPC}}$ in the range $80 \leq d_{\mathrm{SPC}} \leq 500 \mu \mathrm{m}$ in a detector plane $2.5 \mathrm{~mm}$ high and $25 \mathrm{~mm}$ wide, oriented perpendicular to the main flow in the tunnel. 


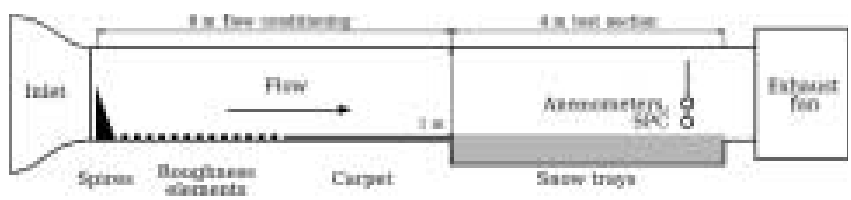

Fig. 1. Schematic view of the wind tunnel experiment. Anemometers are at 0.05 and $0.1 \mathrm{~m}$ above the snow at the start of the experiment. An SPC is at $0.05 \mathrm{~m}$ above the snow at the same streamwise position.

A potential drawback of the wind tunnel arrangement is that the surface is by necessity 'patchy'. That is, sections of differing surface roughness (roughness elements, carpet and then snow) follow each other. A boundary layer which develops over a surface of a specific roughness length and then encounters a second surface roughness will adapt to the new roughness. This adaptation takes the form of an internal boundary layer growing from the upstream edge of the second patch. The interface height of the internal boundary layer, $z_{i}$, is a function of the roughness length of the second surface, in this case snow, and the fetch, $x$, over which the internal boundary layer develops. Arya (2001, p. 326-327) reports that experimental data show

$$
z_{i}=z_{0} a_{i}\left(\frac{x}{z_{0}}\right)^{0.8}
$$

where $a_{\mathrm{i}}$ is an empirical constant, $0.35 \leq a_{\mathrm{i}} \leq 0.75$. The highest anemometer was mounted $0.1 \mathrm{~m}$ above the surface after fetch $x=3 \mathrm{~m}$; in the worst case $a_{i}=0.35$ and the smallest roughness length at which $z_{\mathrm{i}} \geq 0.1 \mathrm{~m}$ is $z_{0}=$ $2.4 \times 10^{-5} \mathrm{~m}$. Roughness lengths smaller than this were therefore rejected as being improbable, as they would require the upper anemometer to be above the interface.

Snow was characterized before the start of drift using several methods. A basic 'field' style classification was made of grain type, snow temperature and snow density (Colbeck and others, 1990). High-spatial-resolution vertical penetrometer readings were taken before experiments using a SnowMicroPen (SMP; Schneebeli and others, 1999). Twodimensional image processing of photomicrographs of at least 30 snow particles allowed characterization by objective criteria such as diameter, dendricity and sphericity. Drift is usually observed after 5-10 min during experiments, depending on the threshold velocity. Comparing measurements of surface particle diameter and snow density just before experiments start, and then after the start of drift, shows that any changes during this short time are too small to detect. Temperatures measured by thermocouples in the snow and free stream typically differed by less than $2 \mathrm{~K}$, which minimizes the turbulent fluxes of sensible heat to and from the snowpack and so reduces metamorphosis.

Grain characteristics are determined from image processing of digitized photomicrographs. The mean diameter of a particle is taken as the mean distance through its centroid to diametrically opposing points every $2^{\circ}$ around the circumference. The mean particle diameter for an experiment is the numerical average of all mean diameters measured from the images, denoted $d_{1}$. Sphericity, SP, and dendricity, DN, of particles are defined from images using the definitions of Lesaffre and others (1998).

The process of snow metamorphosis results in a change of DN from 1 for new snow towards zero for older snow. We

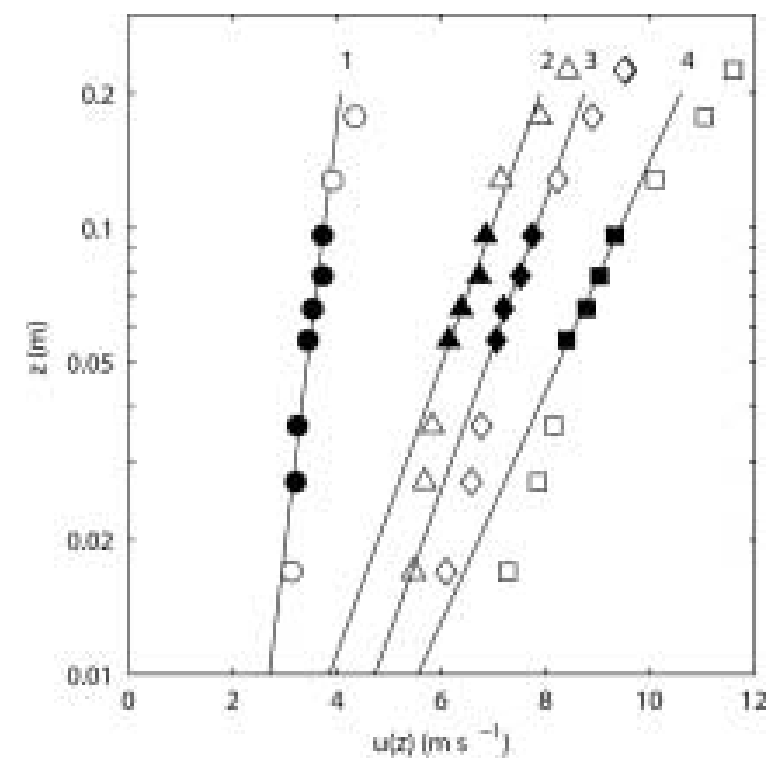

Fig. 2. Velocity profiles over snow. Profiles were measured by dynamic pressure rake over snow on 2 March 2006. Different markers indicate different measurement plateaux. Filled points show data fitted using the log-law (Equation (1)). The fit is limited to $z \leq 0.1 \mathrm{~m}$. Drift occurs in plateaux $2-4$, and data are limited to $0.05 \leq z \leq 0.1 \mathrm{~m}$. The calculated $u_{*}$ and $z_{0}$ are summarized in Table 2 .

distinguish between the two major processes of metamorphosis by describing snow with $\mathrm{DN}<0.5$ and $\mathrm{SP}>0.5$ as snow which is becoming rounded, and snow with $\mathrm{DN}<0.5$ and $\mathrm{SP}<0.5$ as snow which is becoming faceted (Lehning and others, 2002b, fig. 8).

\section{THE BOUNDARY LAYER OVER SNOW}

Example velocity profiles from the rake are plotted in Figure 2. From this plot it is apparent that the lower boundary layer velocities follow the log-law, as they are linear to more than $0.10 \mathrm{~m}$ above the snow surface. In this region they are described by Equation (1) with $R^{2}>0.8$. The resulting $u_{*}$ and $z_{0}$ for the profiles are given in Table 2 . Drift during the measurement plateaux is described by the probability of drift at the SPC, defined as the number of $1 \mathrm{~s}$ intervals during which drift was measured, divided by the duration of the plateau. Both MiniAir anemometers are in the region $z \leq 0.1 \mathrm{~m}$, at least until drift starts, and this confirms that we can apply Equation (1) to those measurements to calculate $u_{*}$ and $z_{0}$. As more data were taken from the anemometers than the rake, all further data presented here use $u_{*}$ and $z_{0}$ calculated from the MiniAir data.

\subsection{Drift threshold}

The mass flux of drifting snow during an experiment is plotted in Figure 3. This shows the friction velocity obtained from the MiniAirs, and the mean mass flux measured by the SPC during each plateau. Instead of a subjective assessment of the drift threshold, either from data (Doorschot and others, 2004) or from observations in the tunnel (Liu and others, 2006), we use the plateau-averaged $u_{*}$ and plateauaveraged SPC mass flux $q_{\text {SPC }}$ to estimate the threshold. An example of a fit to experimental data using Equation (8) is given in Figure 3, which also demonstrates the reason for 
Table 2. Fits to the velocity profiles shown in Figure 2. Velocity data are fitted using Equation (1). $R^{2}$ is the value of the coefficient of determination for the fit. $P$ (drift) is the probability of drift in that plateau

\begin{tabular}{lllll}
\hline Profile & $u_{*}$ & $z_{0}$ & $R^{2}$ & $P($ drift $)$ \\
& $\mathrm{m} \mathrm{s}^{-1}$ & $\mathrm{~mm}$ & & \\
\hline 1 & 0.19 & 0.03 & 0.94 & 0.00 \\
2 & 0.55 & 0.58 & 0.95 & 0.03 \\
3 & 0.55 & 0.30 & 0.98 & 0.21 \\
4 & 0.69 & 0.37 & 0.98 & 0.75 \\
\hline
\end{tabular}

this method. If the threshold had been defined as the first point where drift was detected, the threshold would have been at $u_{*}<0.32 \mathrm{~m} \mathrm{~s}^{-1}$, and would have been defined by a single data point. However, a visual inspection of the whole data series does suggest a threshold at $u_{*} \approx 0.3 \mathrm{~m} \mathrm{~s}^{-1}$. This is also the value found by regression through the whole data series. The threshold is then defined in terms relevant to mass movement, not by a single measurement or a small number of drifting particles.

Because $u_{* t}$ is obtained from a fit to Equation (8), it does not correspond directly to a measurement plateau, and thus has no $z_{0}$ measurement associated with it. The threshold roughness length, $z_{0 t}$, is taken as the linearly interpolated value of $z_{0}$ from the measurements immediately around the threshold. Data are bracketed in the range $\left[u_{* t}\right]$ and $\left[z_{0 t}\right]$ using the friction velocities and roughness lengths measured during the neighbouring measurements. Ambient conditions at the onset of drift were taken as the mean values in these plateaux.

Table 3 details the friction velocity and roughness length at the threshold. A threshold wind speed at $10 \mathrm{~m}$ above the surface, $u_{t}(10)$ is calculated from $z_{0 t}$ and $u_{* t}$ using Equation (1). In Figure $4, z_{0}$ is plotted against $u_{*}$ up to and including the drift threshold. The roughness lengths before the threshold are values measured during the course of the

Table 3. Boundary layer characteristics at saltation threshold for wind tunnel tests

\begin{tabular}{|c|c|c|c|c|c|}
\hline No. & $\begin{array}{l}z_{\mathrm{Ot}} \\
\mathrm{mm}\end{array}$ & $\begin{array}{l}{\left[z_{0 t}\right]} \\
\mathrm{mm}\end{array}$ & $\begin{array}{l}u_{* \mathrm{t}} \\
\mathrm{m} \mathrm{s}^{-1}\end{array}$ & $\begin{array}{l}{\left[u_{* \mathrm{t}}\right]} \\
\mathrm{m} \mathrm{s}^{-1}\end{array}$ & $\begin{array}{c}u_{\mathrm{t}}(10) \\
\mathrm{m} \mathrm{s}^{-1}\end{array}$ \\
\hline 1 & 0.12 & $0.11-0.12$ & 0.69 & $0.67-0.71$ & 19.1 \\
\hline 2 & 0.10 & $0.10-0.10$ & 0.34 & $0.30-0.37$ & 9.4 \\
\hline 3 & 0.09 & $0.06-0.11$ & 0.38 & $0.31-0.45$ & 10.8 \\
\hline 4 & 0.05 & $0.04-0.07$ & 0.27 & $0.25-0.29$ & 8.0 \\
\hline 5 & 0.11 & $0.07-0.15$ & 0.30 & $0.27-0.33$ & 8.3 \\
\hline 6 & \multicolumn{5}{|c|}{ instruments above $z_{\mathrm{i}}$} \\
\hline 7 & 0.07 & $0.05-0.08$ & 0.34 & $0.32-0.36$ & 9.8 \\
\hline 8 & \multicolumn{5}{|c|}{ instruments above $z_{\mathrm{i}}$} \\
\hline 9 & 0.10 & $0.07-0.13$ & 0.37 & $0.32-0.42$ & 10.5 \\
\hline 10 & 0.04 & $0.04-0.05$ & 0.44 & $0.40-0.48$ & 13.3 \\
\hline 11 & 0.13 & $0.12-0.14$ & 0.37 & $0.35-0.41$ & 10.1 \\
\hline 12 & 0.10 & $0.08-0.12$ & 0.30 & $0.25-0.34$ & 8.4 \\
\hline 13 & \multicolumn{5}{|c|}{ instruments above $z_{\mathrm{i}}$} \\
\hline 14 & \multicolumn{5}{|c|}{ instruments above $z_{\mathrm{i}}$} \\
\hline 15 & \multicolumn{5}{|c|}{ instruments above $z_{\mathrm{i}}$} \\
\hline
\end{tabular}

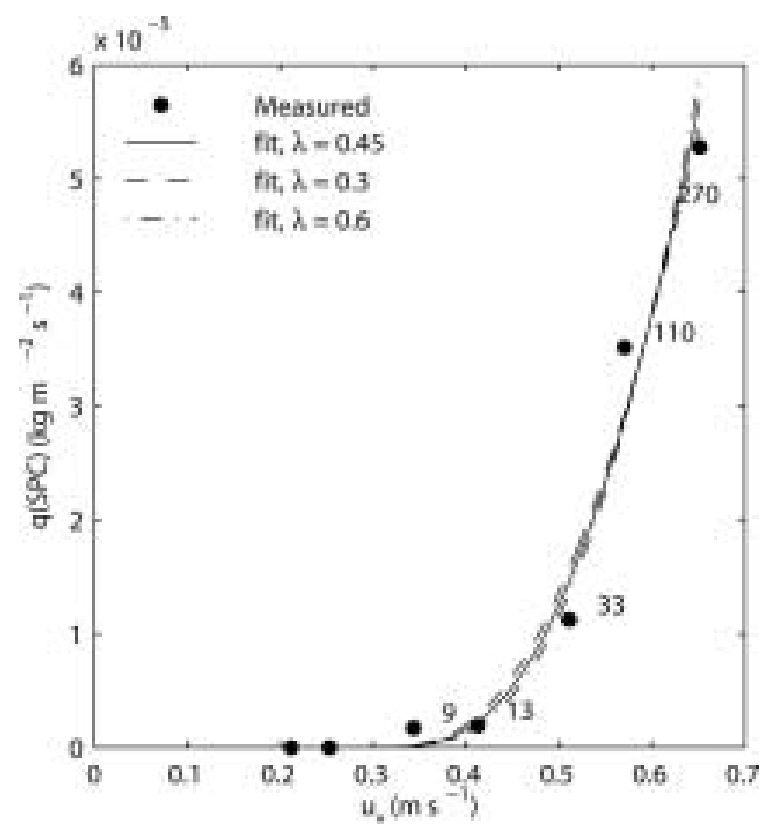

Fig. 3. Drifting-snow mass flux as a function of $u_{*}$. Snow mass flux is averaged over measurement plateaux during measurements on 9 March 2005. Data are fitted using Equation (8). Three different values of $\lambda$ were tested, and $u_{* \mathrm{t}}=0.30 \mathrm{~m} \mathrm{~s}^{-1}$ in each case. The number beside each data point is the total number of observed particles at each point.

experiment. Equation (3) is also plotted with $C=0.021$ and shows that $u_{* \mathrm{t}}$ measured in the wind tunnel is generally $10-20 \%$ higher than would be expected for the measured $z_{0}$, compared to sand and soil measurements. Another set of measurements was made during summer 2005, using low-density, open-celled foam in place of snow. Repeated measurements over the foam, which had a roughness length similar to snow, showed that the uncertainty in $z_{0}$ for $u_{* \mathrm{t}}<0.4 \mathrm{~m} \mathrm{~s}^{-1}$ could be greater than $50 \%$. Owen's model therefore lies within the uncertainty range of all but two data points. Threshold friction velocities obtained for each experiment are not exact because there may be some drift below the height of the SPC at $u_{*} \leq u_{* \mathrm{t}}$. There is also the chance that the SPC simply misses drifting particles at this height as it only occupies $2.5 \%$ of the channel width, although this is unlikely given the time at the plateau.

The value of $z_{0 t}$ measured in the wind tunnel is generally lower than field measurements. It is two orders of magnitude lower than those measured over fresh snow by Doorschot and others (2004) in an Alpine landscape and almost two orders of magnitude lower than those measured at Ice Station Weddell, Antarctica, by Andreas and others (2005). Our measured $z_{0 t}$ are an order of magnitude lower than $z_{0}$ measured during the Surface Heat Budget of the Arctic Ocean field experiment (SHEBA; Andreas and others, 2004). Bintanja and Van den Broeke (1995) measured $z_{0}$ typically 1-2 orders of magnitude higher than our threshold levels. Bintanja and Van den Broeke (1995, fig. 3) show a lower limit to measured data at $z_{0}=0.016 u_{*}^{2} / g$. Note that they used Charnock's (1955) relationship for breaking waves, that is, the form in Equation (3). This gives $C=0.032$, and a lower limit to $z_{0}$ which is $50 \%$ higher than our measurements. Pomeroy and Gray (1990) found $C=0.1203$, giving $z_{0}$ some six times greater than ours. Higher values in natural 


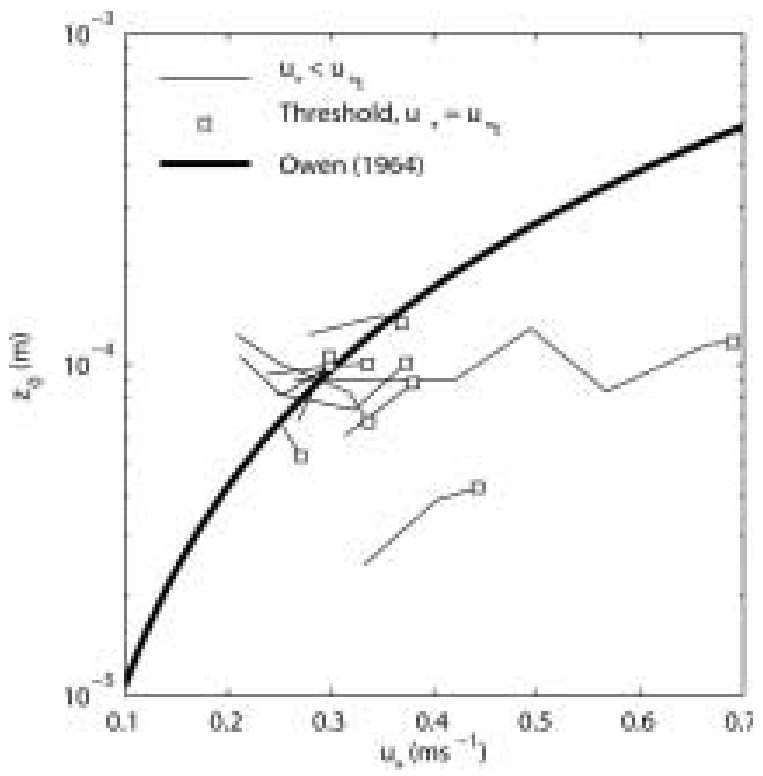

Fig. 4. Values of $z_{0}$ and $u_{*}$ up to and including the drift threshold. Each thin line shows one experiment. Wind velocities were measured by anemometers at two heights. The model for drifting sand and soil of Owen (1964) (Equation (3)) is also shown.

settings compared to the wind tunnel are probably a result of the experimental set-up; the tunnel floor is relatively smooth compared to natural flat surfaces, where topology, sastrugi, vegetation or other obstructions would increase $z_{0}$.

\subsection{Pre-threshold roughness lengths}

Pre-threshold $u_{*}$ and $z_{0}$ normalized by $u_{* t}$ and $z_{0 t}$ are shown in Figure 5. A linear regression fitted by least squares to the data shows that $z_{0}$ is almost constant as $u_{*}$ increases towards the threshold value, so that $z_{0} / z_{0 \mathrm{t}}=0.04 u_{*} / u_{* \mathrm{t}}+0.94$. The regression is heavily influenced by one test with a comparatively high $u_{* \mathrm{t}}$ (17 January 2005). Removing test data gives $z_{0} / z_{0 \mathrm{t}}=-0.34 u_{*} / u_{* \mathrm{t}}+1.3$. The $95 \%$ confidence interval for both cases includes the line $z_{0} / z_{0}$, suggesting that it is highly likely that $z_{0}$ for a particular snow surface is independent of $u_{*}$ until the start of drift. This will be further investigated by systematic measurements of $u_{*}$ and $z_{0}$ over analogous materials.

\subsection{Influence of weather and snow characteristics}

The drift threshold conditions of 15 snow samples have been measured. This gives a dataset of some 9 different snow types, ambient temperatures from -16 to $0^{\circ} \mathrm{C}$ and particle diameters ranging from 0.1 to $3 \mathrm{~mm}$. The ambient conditions and snow characterization for the tests are summarized in Table 1 and compared to threshold conditions in Figure 6. Coefficients of determination from linear regressions are also given.

Aerodynamic roughness over surfaces covered in arrays of objects is partly determined by the particle profile presented to the wind, and partly by the particle spacing (Wooding and others, 1973). These may be functions of snow particle diameter and density. Magono and Lee (1966) showed that cloud temperature and humidity change the form of fresh snow particles, so we might also expect weather conditions to influence $z_{\mathrm{Ot}}$.

From Figure $6 \mathrm{e}-\mathrm{h}$ there is no indication of a link between the ambient conditions, snow properties and $z_{0 t}$. This is

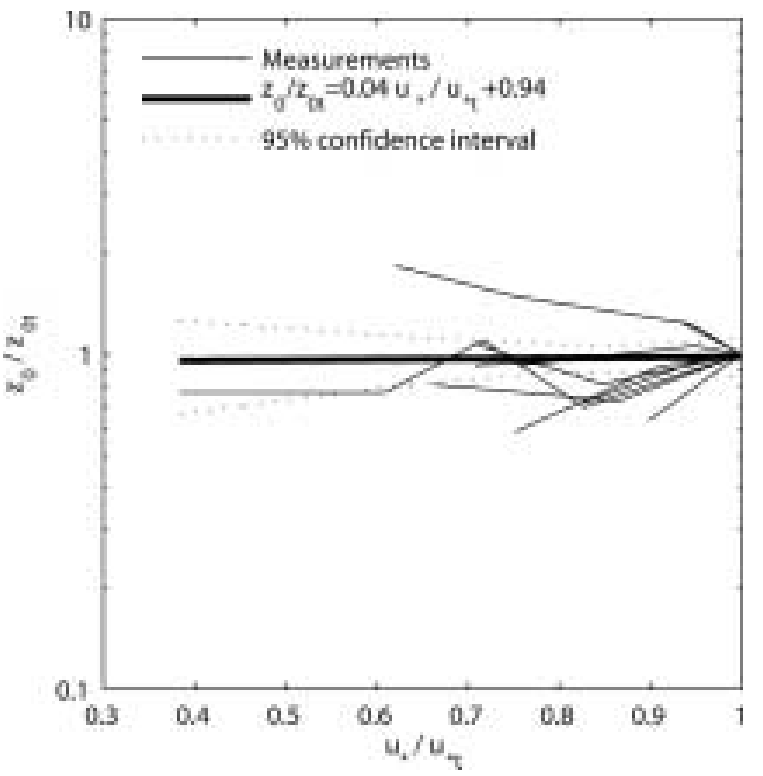

Fig. 5. Values of $z_{0}$ and $u_{*}$ shown in Figure 4 normalized by the saltation threshold values for each experiment.

probably because we cannot account for the effect of differences between cloud conditions, which drive the formation of snow crystals, and the near-ground conditions measured here.

The highest observed correlation is between $u_{* \mathrm{t}}$ and the snow density, where $R^{2}=0.91$, but this could be spurious, given the strong influence on the resulting fit of the high density and $u_{* \mathrm{t}}$ of just one test (17 January 2005). The next highest correlation, $R^{2}=0.51$, was seen between $u_{* \mathrm{t}}$ and $d_{1}$, and may also be prone to influence from one test more than others. However, both the snow density and particle diameter are tested for their use as predictor variables for $u_{* \mathrm{t}}$ in section 5. A low correlation $\left(R^{2}=0.21\right)$ was obtained between $u_{* t}$ and the ambient temperature. Kirchner and others (2001) show that strain rates at which an ice matrix behaves as a ductile material are higher at high temperatures than lower temperatures. Assuming strain rates at the snow surface are similar in all drift experiments, this would mean that a warmer surface is less likely to fail and eject a particle, so that warmer surfaces would be expected to have higher $u_{* t}$. There is a trend toward this in Figure $6 \mathrm{a}$, but again the small size of the dataset limits the reliability of a simple linear regression.

\subsection{Surface penetration resistance}

Snow surface penetration resistance was measured before experiments using a SMP. Figure 7 shows the mean force applied by the SMP compared to the threshold shear, $\tau_{* \mathrm{t}}=\rho u_{* \mathrm{t}}{ }^{2}$. The mean force is measured when the SMP tip is 4-5 mm into the snow, and represents complete immersion of the SMP tip. The SMP measures the total force required to break contact points and move grains within the snow. Aerodynamic entrainment at the surface during saltation is also a process where bonds are broken, so a correlation might be expected. The shear required to start drift does tend to increase with penetration resistance, although with low correlation $\left(R^{2}=0.27\right)$. This suggests that a linear regression is too simplistic a model. 

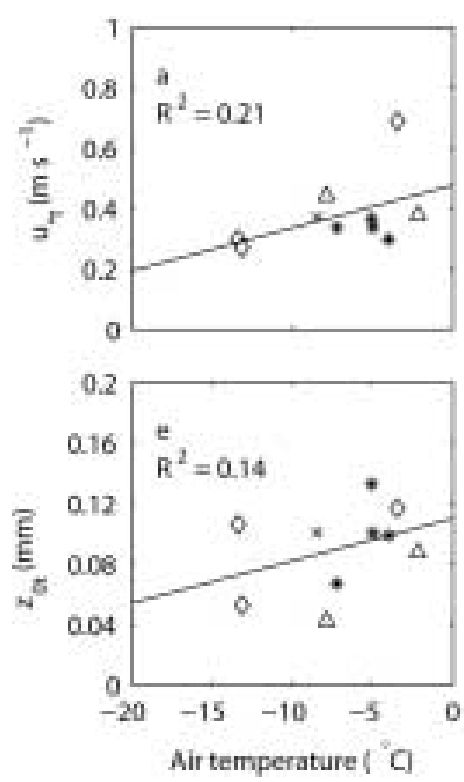

New and decomposing snaw; DN $>0.5$

Rather faceted: DN $<0.5$, $5 P<0.5$

Rather rounded: DN $<0.5,5 P>0.5$

Unclassified
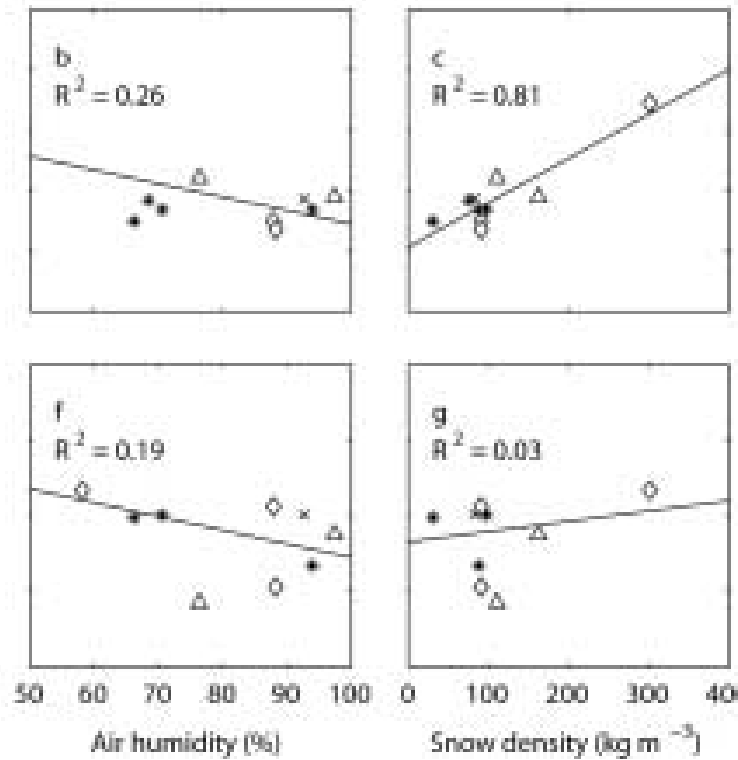
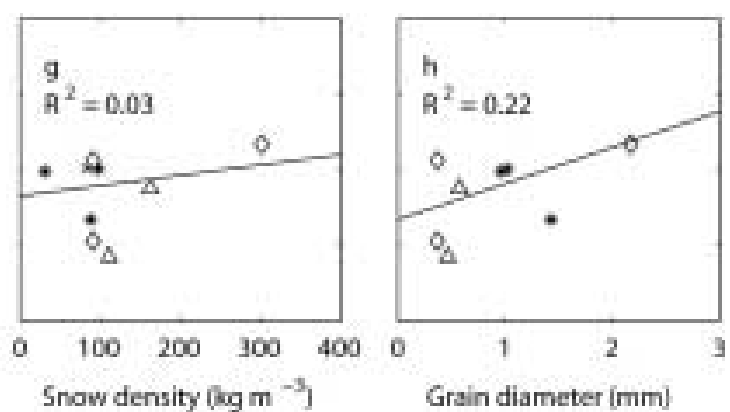

Fig. 6. Influence of ambient conditions and snow properties on saltation threshold conditions.

\subsection{Airborne grain sizes}

Grain sizes of airborne snow were measured by the SPC at $0.05 \mathrm{~m}$ above the snow surface. Budd and others (1966), Schmidt (1982) and Nishimura and Nemoto (2005) demonstrate that the size distribution of airborne grains can be fitted using a two-parameter gamma-distribution function, where the probability of observing a grain of diameter $d$ is given by

$$
P(d)=\frac{d^{\alpha-1}}{\beta^{\alpha} \Gamma(\alpha)} \mathrm{e}^{d / \beta}
$$

The mean grain diameter is given by the product $\alpha \beta$.

Figure 8 compares the mean grain diameter seen on the surface with that detected by the SPC. The mean drifting grains seen immediately after the drift threshold by the SPC were typically of diameter $100-175 \mu \mathrm{m}$. These were calculated from SPC records using Equation (13). They do not correlate with surface grain sizes, as given in Table 1. This is surprising as the grain size and snow density affect the threshold, but the drifting particles are ultimately similar.

Schmidt (1982) and Nishimura and Nemoto (2005) also measured drift on flat surfaces after snowfall. They measured drifting particles with mean diameters in the range 100$200 \mu \mathrm{m}$, using similar equipment to ours, although they did not relate these back to a characterization of the snow on the ground. Our fetch is only $3 \mathrm{~m}$, compared to several hundred or thousand metres in field experiments, but observed particle diameters are very similar. This suggests either that particles are rapidly fracturing before they reach the detector, or that smaller ice particles are selectively entrained from the snow surface. Simulations using the model of Doorschot and others (2004) show that the jump length of a $150 \mu \mathrm{m}$ diameter particle, reaching $5 \mathrm{~cm}$ above the surface of fresh snow, is of the order of $1 \mathrm{~m}$. If particles are rebounding from the surface on every impact, the particles are likely to have had three jumps before reaching the detector. This number of impacts may be enough to reduce the size of the particles seen during the characterization to the size of particles at the SPC, giving the relationship seen in Figure 8, but we cannot track individual particles through the tunnel to investigate this. For lowdensity snow at velocities only slightly higher than the threshold, aerodynamic entrainment might be expected to dominate over rebound (Doorschot, 2002). Because smaller particles have smaller bonds to their neighbours and lower mass, and are therefore easier to entrain from the surface, it is most likely that it is the smaller particles which move at the drift threshold.

This size discrepancy has implications for snow transport in mountainous regions. During a storm all sizes of particles are moved, both from the surface and the snow which has not yet reached the ground. This may result in increased deposition of snow on lee slopes, causing 'wind slab'. This may be combined with an extra impulse normal to the surface from wind eddies, which would further increase packing of deposits, independent of exposition, raising the density of the slab. In comparison, when significant wind first occurs after a snowfall, smaller particles or broken crystals are apparently entrained and transported. As these are then deposited back into the snow, this would probably cause an increased density at the surface of the snow, a 'wind crust' (see Colbeck and others, 1990). Experiments in the wind tunnel have not yet been able to reproduce a significant wind crust, although surface erosion features, such as striations, have been observed.

\section{COMPARISON TO THRESHOLD ALGORITHMS}

Experiments by Bagnold (1941) and Greeley and Iversen (1985) measured the threshold friction velocity of spherical and angular particles such as sand, clover seeds and nut shells. However, snow is not spherical. A solution to this is to convert the shapes measured using image processing to a circle with equivalent aerodynamic properties. The diameter 

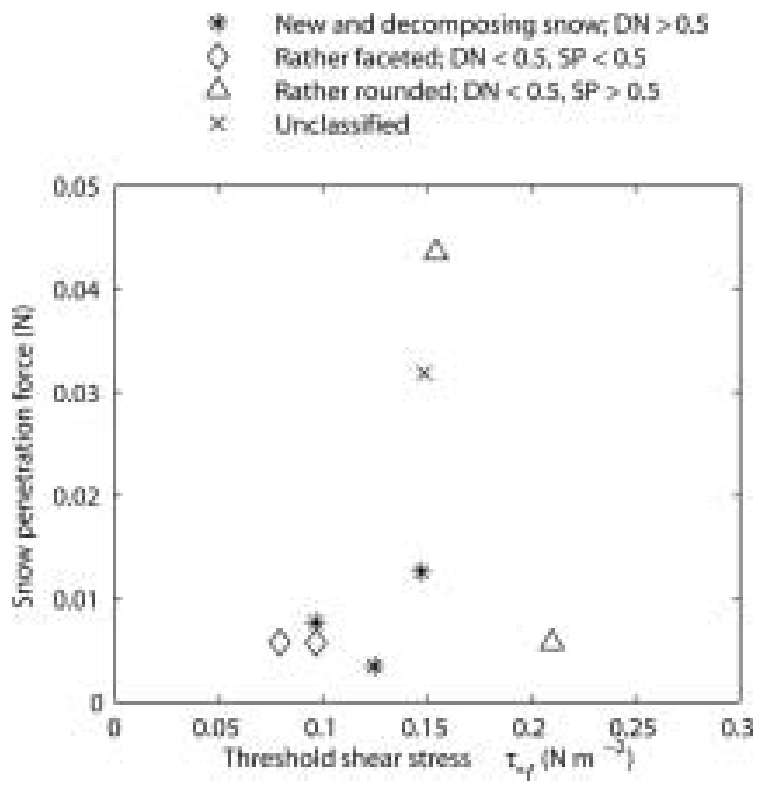

Fig. 7. Surface penetration resistance compared to threshold aerodynamic shear stress. Penetration resistance is measured by SMP.

of the equivalent circle is the hydraulic diameter, $d_{\mathrm{h}}$. The hydraulic diameter is calculated as $d_{\mathrm{h}}=4 \bar{a} / \bar{p}$, where $\bar{a}$ is the mean area and $\bar{p}$ the mean perimeter of the snow in a sample.

Results from our measurements comparing $d_{\mathrm{h}}$ with $u_{* \mathrm{t}}$ are shown in Figure 9, and show that the measured threshold, $u_{* t}$, is well predicted using Equation (9) with $A=0.18$. The smallest particle size observed on the surface was $d_{\mathrm{h}}=0.26 \mathrm{~mm}$, and the lowest threshold friction velocity was $0.28 \mathrm{~m} \mathrm{~s}^{-1}$. Taking $\nu$ as $1.48 \times 10^{-5} \mathrm{Pas}$ at $-10^{\circ} \mathrm{C}$ and $83.5 \mathrm{kPa}$ ambient pressure, the lowest particle Reynolds number was 4.9 at the start of saltation. Measurements from Greeley and Iversen (1985, fig. 3.6) show that the threshold parameter, $A$, is constant for $\operatorname{Re}_{* d} \geq 5$ at 0.1 for noncohesive, granular materials.

Schmidt's algorithm (Equation (10)) was developed for cohesive ice particles, but the parameters have been tuned for snow from field observations of drift, and hence we use the diameter of the snow calculated from image processing, $d_{1}$. Image processing is also used to calculate the mapped sphericity, SP. Air density is obtained from measured temperature and pressure during the test. The bond diameter, $d_{\mathrm{b}}$, and three-dimensional coordination number, $N_{3}$, must be estimated or measured. Brown and others (1999) assumed $d_{\mathrm{b}}=d / 10$ for fresh snow, increasing to $0.15-0.30$ after 7 days of isothermal metamorphosis. Keeler (1969) found $d_{\mathrm{b}}<d / 20$ for snow 2 days old, but reported no data for snow younger than this. We assume a range of $0.1 \leq d_{\mathrm{b}} / d_{1} \leq 0.4$, with no correction for density or age, and use this to bracket our prediction. The correlation given in Lehning and others (2002a) is used to calculate $N_{3}$ from the bulk density of the snow, $\rho_{\mathrm{s}}$ :

$$
\begin{aligned}
N_{3}= & 1.43-7.56 \times 10^{-5} \rho_{\mathrm{s}}+5.15 \times 10^{-5} \rho_{\mathrm{s}}^{2} \\
& -1.73 \times 10^{-7} \rho_{\mathrm{s}}^{3}+1.81 \times 10^{-10} \rho_{\mathrm{s}}^{4} .
\end{aligned}
$$

Equation (14) gives $N_{3}=1.53$ for snow of density $50 \mathrm{~kg} \mathrm{~m}^{-3}$, increasing to 1.78 at $100 \mathrm{~kg} \mathrm{~m}^{-3}$. Brown and others (1999) assume $\mathrm{N}_{3}=2.5$.

Figure 10a shows that $u_{* \mathrm{t}}$ is well predicted where it was assumed $d_{\mathrm{b}}=d_{\mathrm{l}} / 10$, and so the bond strength is predicted

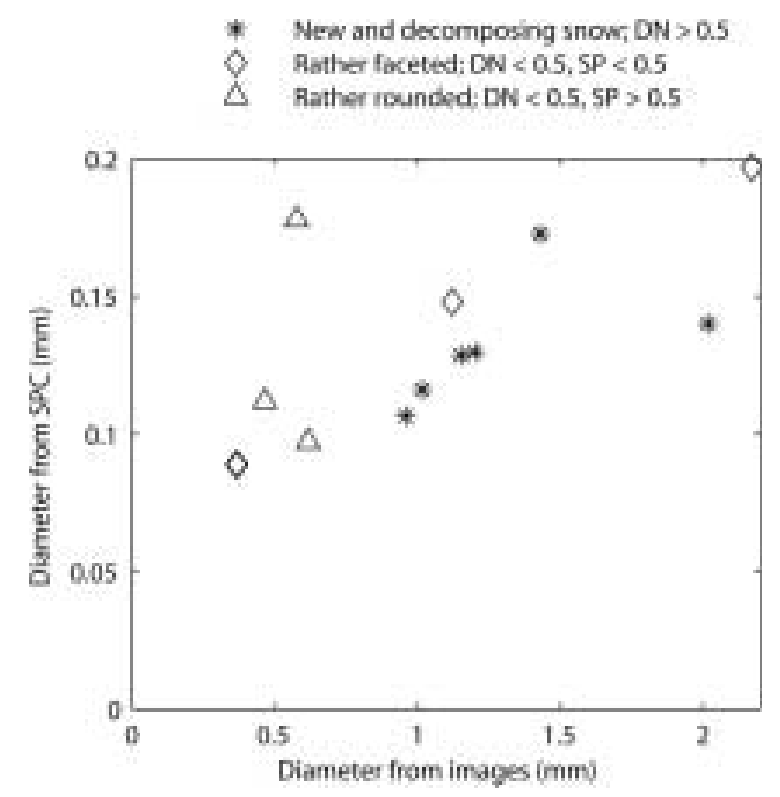

Fig. 8. Comparison of diameters of airborne and surface snow particles. Airborne particle diameters are calculated using a fit to SPC data (Equation (13)). Surface particle diameters are measured from images.

to be lowest. Predictions using the mean values lead to significant over-prediction. Figure $10 \mathrm{~b}$ shows the calculated $u_{* \mathrm{t}}$ if $A=0.023$ and $B=3.45 \times 10^{-3}$ in Equation (10). These constants are implemented in SNOWPACK 9.1. The predicted range of $u_{* \mathrm{t}}$ has reduced, and predictions assuming the smallest bond sizes agree well with the measured values. Uncertainty remains in both cases, though, as $d_{\mathrm{b}}$ is unknown. From Equation (10), $d_{\mathrm{b}}$ and $d$ of the surface particles are more important for calculating the threshold friction velocity than the sphericity, SP.

A comparison with Li and Pomeroy (1997a) requires an air temperature at $2 \mathrm{~m}$, which is unknown. Assuming that in the

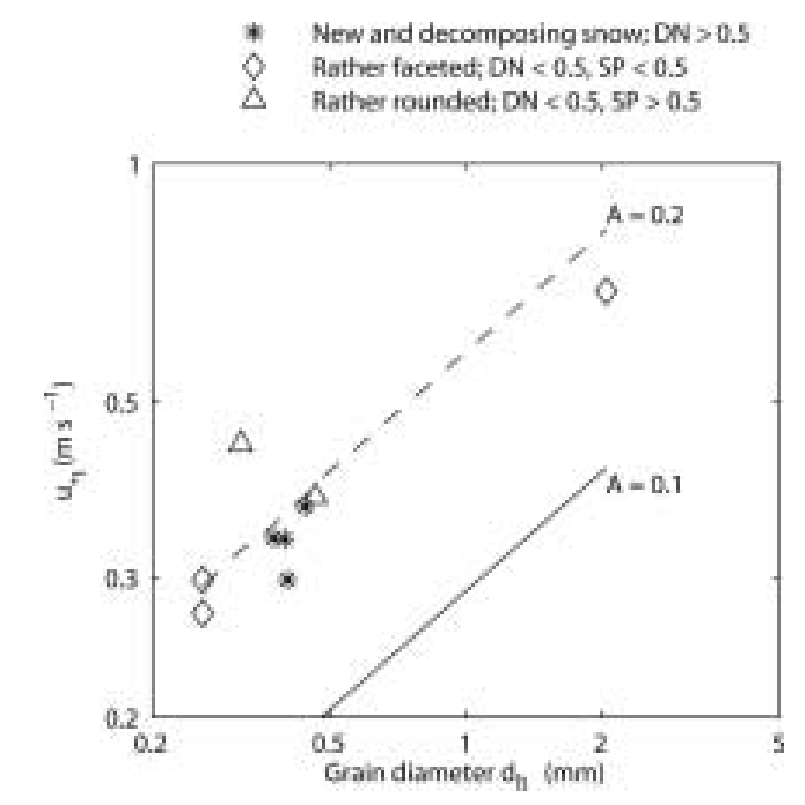

Fig. 9. Measurements of $u_{* t}$ as a function of surface particle hydraulic diameter, $d_{\mathrm{h}}$. The lines are Equation (9) (Bagnold, 1941) with threshold parameter $A=0.1$ (solid line) and $A=0.2$ (dashed line). 

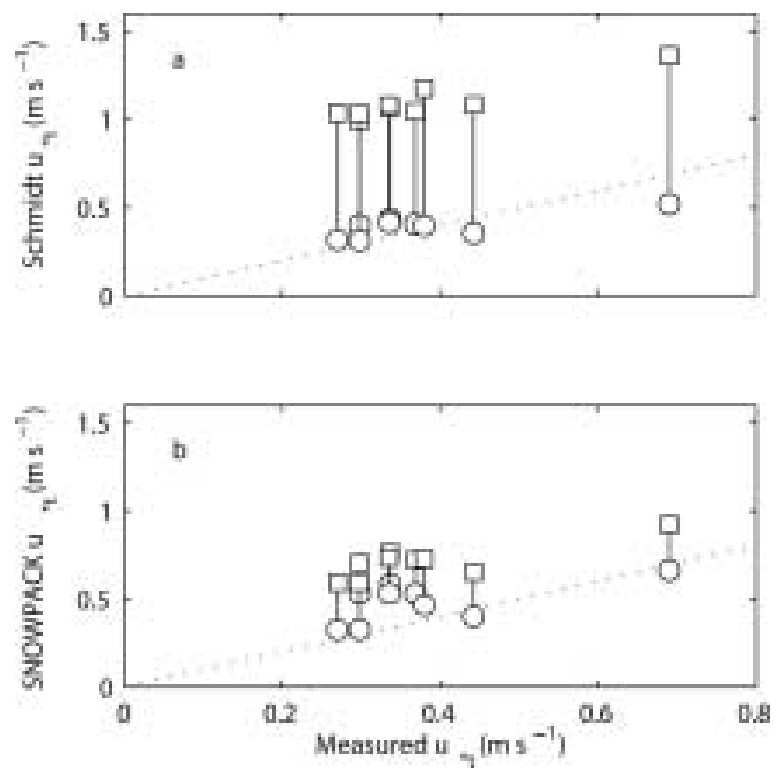

Fig. 10. Comparison of predicted and measured $u_{* t}$. (a) Schmidt (1980) formulation; and (b) SNOWPACK 9.1 formulation. Circles show predictions assuming $d_{1} / d_{b}=10$, and squares assume $d_{\mathrm{l}} / d_{\mathrm{b}}=2.5$. The cases where the calculated and measured thresholds are identical are shown with dotted lines.

wind tunnel there is negligible temperature gradient normal to the surface, $T_{\mathrm{a}}$ approximates to the temperature at the inlet to the test section. A comparison between Equation (11) and $u_{t}(10)$ calculated from the wind tunnel threshold results is shown in Figure 11. Data from the wind tunnel suggest that at temperatures near $0^{\circ} \mathrm{C}$, Equation (11) under-predicts the threshold. The original data in Li and Pomeroy (1997a) show that at $-5<T_{\mathrm{a}}<0$, the $95 \%$ confidence interval extends over the range $3<u_{\mathrm{t}}(10)<14 \mathrm{~m} \mathrm{~s}^{-1}$, which leaves only one of our data points as an outlier. Given that the dataset used to obtain Equation (11) is based on 6 years of hourly data from 16 weather stations, it is unreasonable to propose a new set of coefficients based on just 15 wind tunnel data points.

Our data are not inconsistent with Equation (11), but it appears that the predictive power of a statistical analysis is limited in comparison to the approaches of Schmidt (1980) and Bagnold (1941). Figures 6, 9 and 10 strongly suggest that directly measured snow size and density information is a more useful predictor for the drift threshold velocity than temperature some distance above the snow surface.

\section{CONCLUSIONS}

A wind tunnel for measuring boundary layer profiles over natural snow under controlled conditions has been commissioned at SLF in Davos. Drift threshold conditions have been measured during a series of experiments with smooth, fresh snow and compared to measured snow properties and characteristics. A routine has been developed to automatically recognize the drift threshold from boundary layer data and point measurements of drifting-snow mass flux. The threshold $u_{*}$ were found to vary between 0.27 and $0.69 \mathrm{~m} \mathrm{~s}^{-1}$. Roughness lengths at the threshold varied from 0.04 to $0.13 \mathrm{~mm}$, and the range of both $u_{*}$ and $z_{0}$ may increase as more snow samples are tested.

Wind-tunnel values of $z_{0}$ are smaller than most field measurements, although similar to lowest values measured

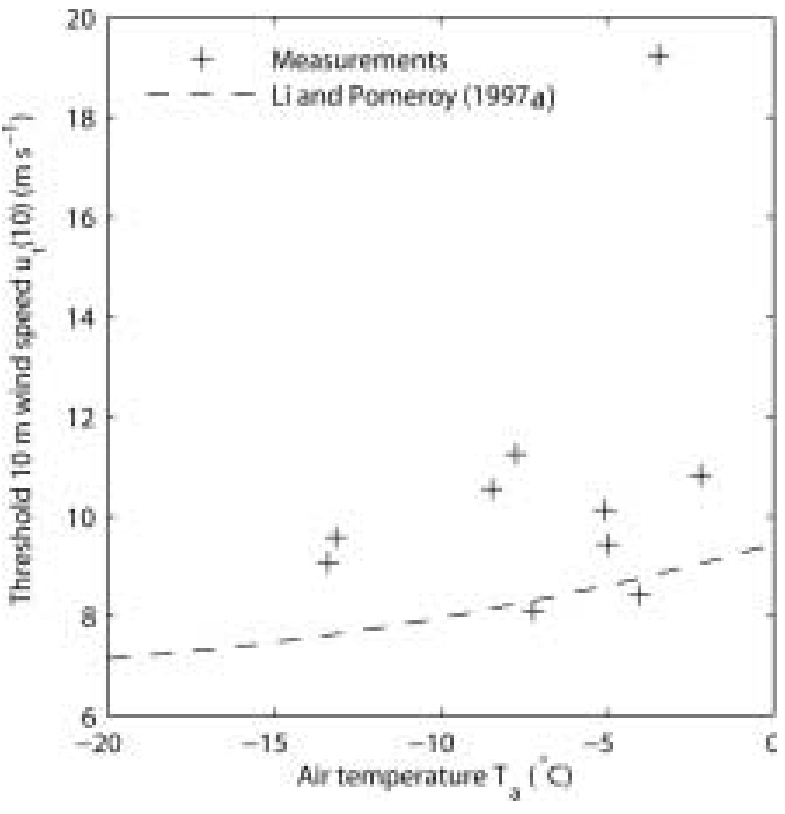

Fig. 11. Drift threshold wind speeds at $10 \mathrm{~m}$ above the surface as a function of air temperature. Wind tunnel data are extrapolated from measured $u_{* t}$ and $z_{0 \mathrm{t}}$. The dashed line shows Equation (11) (Li and Pomeroy, 1997a).

over Antarctic snow-covered ice with minimal topographical influences. As $u_{*}$ increased toward $u_{* t}, z_{0}$ was found to change slightly, and we expect that a larger dataset will show that a particular snow surface generally has a constant $z_{0}$ until the onset of drift, as with sand or other rough surfaces. The roughness length at the drift threshold was well predicted using the approach of Owen (1964), with $C=0.021$, as has been found for sand and soil. Two measurements, one with depth hoar and the other with highly broken particles, show lower $z_{0 t}$ than expected. The reason for this difference is not clear.

Threshold algorithms based on force balance (Bagnold, 1941) show that the drift threshold for new and decomposing snow is well predicted using the particle hydraulic diameter and $A \approx 0.18$. This is $80 \%$ greater than found for non-cohesive, granular material such as sand. The threshold friction velocity predicted by Schmidt's algorithm using mean particle form information from photomicrographs was found to be $\approx 100 \%$ larger than the observed mean value in the wind tunnel. A modified formulation as used in SNOWPACK 9.1 over-predicted the threshold by $\approx 50 \%$. The predicted threshold using both formulations is strongly influenced by the presumed bond size. However, assuming small bond sizes in both formulations resulted in good agreement. Models based on Schmidt's algorithm can bound $u_{* \mathrm{t}}$ only if the coordination number, particle and bond diameter are accurately described by models which reflect the variation found in a snowpack. A third threshold model using wind speeds at $10 \mathrm{~m}$ above the surface was also compared to our data (Li and Pomeroy, 1997a). Results lie within the confidence interval of that correlation, which was originally developed from data obtained from weather stations in the Canadian Prairies.

Grain sizes measured by an SPC at $0.05 \mathrm{~m}$ above the snow surface directly after the start of drift were fitted using a gamma distribution. This gave a mean particle diameter in the range $100-175 \mu \mathrm{m}$, independent of the surface particle 
size. The airborne particle diameter is the same as has been found in field experiments both in Antarctica and in Wyoming, USA. Threshold wind speeds at $10 \mathrm{~m}$ above the surface, predicted assuming a log-law wind profile and our measured $u_{* \mathrm{t}}$ and $z_{0 \mathrm{t}}$, are similar to those found over flat terrain in Canada. Taken together this indicates that despite the short fetch in the wind tunnel, our results mirror those found in natural conditions.

We now intend to further develop our wind tunnel to validate drifting-snow models (Doorschot and Lehning, 2002; Nemoto and Nishimura, 2004) and to investigate roughness lengths with drift.

\section{ACKNOWLEDGEMENTS}

This work was partially financed by the Swiss National Foundation. C. Fierz advised us on snow characterization and SNOWPACK, and all in the Snow Physics group at SLF helped with interpreting snow data. T. Exner, R. Grant, D. Ambühl, V. Smith, A. Craig and the SLF Workshop were invaluable for help preparing the wind tunnel and the techniques we applied. We thank K. Nishimura and M. Nemoto for their assistance in January 2005. J. McElwaine helped develop our threshold regression technique. The scientific editor, R. Naruse, and two anonymous reviewers provided valuable suggestions for improvements to this paper. Niigata Electric provided an SPC-S7.

\section{REFERENCES}

Andreas, E.L. 1987. A theory for the scalar roughness and the scalar transfer coefficients over snow and sea ice. Bound.-Layer Meteorol., 38(1-2), 159-184.

Andreas, E.L., R.E. Jordan, P.S. Guest, O.G. Persson, A.A. Grachev and C.W. Fairall. 2004. Roughness lengths over snow. In 18th Conference on Hydrology of the American Meteorological Society, Seattle, WA, 11-15 January 2004. Washington, DC, American Meteorological Society. CD-ROM.

Andreas, E.L., R.E. Jordan and A.P. Makshtas. 2005. Parameterizing turbulent exchange over sea ice: the Ice Station Weddell results. Bound.-Layer Meteorol., 114(2), 439-460.

Arya, S.P.S. 2001. Introduction to micrometeorology. San Diego, CA, Academic Press.

Bagnold, R.A. 1941. The physics of blown sand and desert dunes. London, Methuen and Co.

Bintanja, R. and M.R. van den Broeke. 1995. Momentum and scalar transfer coefficients over aerodynamically smooth Antarctic surfaces. Bound.-Layer Meteorol., 74(1-2), 89-111.

Box, J.E., D.H. Bromwich and L.-S. Bai. 2004. Greenland ice sheet surface mass balance for 1991-2000: application of Polar MM5 mesoscale model and in-situ data. J. Geophys. Res., 109(D16), D16105. (10.1029/2003JD004451.)

Brown, R.L., M.Q. Edens and M. Barber. 1999. Mixture theory of mass transfer based upon microstructure. Defence Sci. J., 49(5), 393-409.

Budd, W.F., R.J. Dingle and U. Radok. 1966. The Byrd Snow Drift Project: outline and basic results. In Rubin, M.J., ed. Studies in Antarctic meteorology. Washington, DC, American Geophysical Union, 71-134. (Antarctic Research Series 9.)

Charnock, H. 1955. Wind stress on a water surface. Q.J.R. Meteorol. Soc., 81, 639-640.

Cline, D.W. 1997. Snow surface energy exchanges and snowmelt at a continental, midlatitude Alpine site. Water Resour. Res., 33(4), 689-701.
Colbeck, S.C. and 7 others. 1990. The international classification for seasonal snow on the ground. Wallingford, Oxon., International Association of Hydrological Sciences. International Commission on Snow and Ice.

Doorschot, J.J. 2002. Mass transport of drifting snow in high Alpine environments. (PhD thesis, Swiss Federal Institute of Technology, Zürich.)

Doorschot, J.J. and M. Lehning. 2002. Equilibrium saltation: mass fluxes, aerodynamic entrainment, and dependence on grain properties. Bound.-Layer Meteorol., 104(1), 111-130.

Doorschot, J.J., M. Lehning and A. Vrouwe. 2004. Field measurements of snow-drift threshold and mass fluxes, and related model simulations. Bound.-Layer Meteorol., 113(3), 347-368.

Garen, D.C. and D. Marks. 2005. Spatially distributed energy balance snowmelt modelling in a mountainous river basin: estimation of meteorological inputs and verification of model results. J. Hydrol., 315(1-4), 126-153.

Garratt, J.R. 1994. The atmospheric boundary layer. Cambridge, Cambridge University Press.

Greeley, R. and J.D. Iversen. 1985. Wind as a geological process on Earth, Mars, Venus and Titan. Cambridge, Cambridge University Press.

Keeler, C.M. 1969. The growth of bonds and the increase of mechanical strength in a dry seasonal snow-pack. J. Glaciol., 8(54), 441-450.

Kirchner, H.O.K., G. Michot, H. Narita and T. Suzuki. 2001. Snow as a foam of ice: plasticity, fracture and the brittle-to-ductile transition. Philos. Mag. A, 81(9), 2161-2181.

Kobayashi, S. 1969. Measurements of the wind drag force of the snow surface. Low Temp. Sci., Ser. A., 27, 87-97. [In Japanese with English summary.]

Kobayashi, D. 1972. Studies of snow transport in low-level drifting snow. Contrib. Inst. Low Temp. Sci., Ser. A., 24.

König, G. 1985. Roughness length of an Antarctic ice shelf. Polarforschung, 55(1), 27-32.

Kunstmann, H. and C. Stadler. 2005. High resolution distributed atmospheric-hydrological modelling for Alpine catchments. J. Hydrol., 314(1-4), 105-124.

Lehning, M., J. Doorschot and P. Bartelt. 2000. A snowdrift index based on SNOWPACK model calculations. Ann. Glaciol., 31, 382-386

Lehning, M., P. Bartelt, B. Brown, C. Fierz and P. Satyawali. 2002a. A physical SNOWPACK model for the Swiss avalanche warning. Part II. Snow microstructure. Cold Reg. Sci. Technol., 35(3), 147-167.

Lehning, M., P. Bartelt, B. Brown and C. Fierz. 2002b. A physical SNOWPACK model for the Swiss avalanche warning. Part III. Meteorological forcing, thin layer formation and evaluation. Cold Reg. Sci. Technol., 35(3), 169-184.

Lesaffre, B., E. Pougatch and E. Martin. 1998. Objective determination of snow-grain characteristics from images. Ann. Glaciol., 26, 112-118.

Li, L. and J.W. Pomeroy. 1997a. Estimates of threshold wind speeds for snow transport using meteorological data. J. Appl. Meteorol., 36(3), 205-213.

Li, L. and J.W. Pomeroy. 1997b. Probability of occurrence of blowing snow. J. Geophys. Res., 102(D18), 21,955-21,964.

Liston, G.E. and M. Sturm. 1998. A snow-transport model for complex terrain. J. Glaciol., 44(148), 498-516.

Liu, X., Z. Dong and X. Wang. 2006. Wind tunnel modeling and measurements of the flux of wind-blown sand. J. Arid Environ., 66, 657-672.

Maeno, N., K. Nishimura, K. Sugiura and K. Kosugi. 1995. Grain size dependence of eolian saltation lengths during snow drifting. Geophys. Res. Lett., 22(15), 2009-2012.

Magono, C. and C.W. Lee. 1966. Meteorological classification of natural snow crystals. J. Fac. Sci., Hokkaido Imp. Univ., Sapporo, Japan, 2(4), 321-335. 
Marks, D. and J. Dozier. 1992. Climate and energy exchange at the snow surface in the alpine region of the Sierra Nevada. 2. Snow cover energy balance. Water Resour. Res., 28(11), 3043-3054.

Nemoto, M. and K. Nishimura. 2004. Numerical simulation of snow saltation and suspension in a turbulent boundary layer. J. Geophys. Res., 109(D18), D18206. (10.1029/2004JD004657.)

Nishimura, K. and J.C.R. Hunt. 2000. Saltation and incipient suspension above a flat particle bed below a turbulent boundary layer. J. Fluid Mech., 417(1), 77-102.

Nishimura, K. and M. Nemoto. 2005. Blowing snow at Mizuho station, Antarctica. Philos. Trans R. Soc., London, 363(1832), 1647-1662.

Nishimura, K., K. Sugiura, M. Nemoto and N. Maeno. 1998. Measurements and numerical simulations of snow-particle saltation. Ann. Glaciol., 26, 184-190.

Oura, H., D. Kobayashi and S. Kobayashi. 1967. Characters of the wind-speed profile during drifting snow. Low Temp. Sci., Ser. A., 25, 73-88. [In Japanese with English summary.]

Owen, P.R. 1964. Saltation of uniform grains in air. J. Fluid Mech., 20(2), 225-242.

Pomeroy, J.W. and D.M. Gray. 1990. Saltation of snow. Water Resour. Res., 26(7), 1583-1594.

Reijmer, C.H., E.V. Meijgaard and M.R. van den Broeke. 2003. Roughness length for momentum and heat over Antarctica in a regional atmospheric climate model. In Proceedings of the Seventh Conference on Polar Meteorology and Oceanography and Joint Symposium on High-Latitude Climate Variations, 12 16 May 2003, Hyannis, Massachusetts. Washington, DC, American Meteorological Society. CD-ROM.
Schlichting, H. 2003. Boundary layer theory. Eighth edition, corr. second printing. Berlin, Springer-Verlag.

Schmidt, R.A. 1980. Threshold wind-speeds and elastic impact in snow transport. J. Glaciol., 26(94), 453-467.

Schmidt, R.A. 1982. Vertical profiles of wind speed, snow concentration and humidity in blowing snow. Bound.-Layer Meteorol., 23(2), 223-246.

Schneebeli, M., C. Pielmeier and J.B. Johnson. 1999. Measuring snow microstructure and hardness using a high resolution penetrometer. Cold Reg. Sci. Technol., 30(1-3), 101-114.

Shao, Y. and A. Li. 1999. Numerical modelling of saltation in the atmospheric surface layer. Bound.-Layer Meteorol., 91(2), 199-225.

Shao, Y. and M.R. Raupach. 1992. The overshoot and equilibration of saltation. J. Geophys. Res., 97(D18), 20,559-20,564.

Sørensen, M. 1991. An analytical model of wind-blown sand transport. Acta Mech., 1 (Suppl.), 67-81.

Stearns, C.R. and G.A. Weidner. 1993. Sensible and latent heat flux estimates in Antarctica. In Bromwich, D.H. and C.R. Stearns, eds. Antarctic meteorology and climatology: studies based on automatic weather stations. Washington, DC, American Geophysical Union, 109-138. (Antarctic Research Series 61.)

Stull, R.B. 1988. An introduction to boundary layer meteorology. Dordrecht, etc., Kluwer Academic Publishers.

Tabler, R.D. 1980. Self-similarity of wind profiles in blowing snow allows outdoor modeling. J. Glaciol., 26(94), 421-434.

Wooding, R.A., E.F. Bradley and J.K. Marshall. 1973. Drag due to regular arrays of roughness elements of varying geometry. Bound.-Layer Meteorol., 5(3), 285-308.

MS received 8 July 2005 and accepted in revised form 8 August 2006 